\title{
SOCIAL FACILITATION IN FINGER MAZE LEARNING ${ }^{1}$
}

\author{
MASAKAZU MIYAMOTO2 \\ Tokiwa Gakuen College ${ }^{3}$
}

\begin{abstract}
This experiment tested the hypothesis that the mere presence of an observer would facilitate performance on simple mazes and hinder performance on complex mazes. Sixty female students traversed either a multiple T-maze or a multiple +-maze either with or without an observer. The factors of maze-type and observer-presence did not interact in a manner consistent with previous researches. On both mazes, the "observed" subject made more errors and needed more trials to reach the criterion than the "alone" subject.
\end{abstract}

One of the basic problems in experimental social psychology is that the behavior of a person can be substantially affected in the mere passive presence of another. Recently, Zajonc (1965, 1969) conducted a thorough review of the existing evidence relating to social facilitation, and integrated the contradictory results: In some studies the presence of others improved individual performance, while in others the reverse occurred. He proposed that the presence of others increases the individual's general arousal which, in turn, enhances the emission of the dominant responses. Zajonc pointed out that during the acquisition of new responses, that is "learning ", incorrect responses have the highest probability of occurrence and so are dominant. However, during performance of well-learned responses, correct responses become more probable, or dominant. Therefore if the dominant responses are correct, performance is im-

1 Portions of the research described here were presented in the proceedings of the $42 \mathrm{nd}$ annual convention of Japanese Psychological Association.

2 The author wishes to express their gratitude to Dr. M. Baba, Ibaraki University, and Mr. T. Toole for their critical reading of the manuscript and valuable comments.

Request for reprints should be sent to Masakazu Miyamoto, Faculty of Education, Gifu University, Vagara, Gifu, 502 Japan.

${ }^{3}$ Now at Gifu University. proved, while if they are incorrect, it is actually impaired. In learning situations many studies support Zajonc's proposal (Cottrell, Rittle, \& Wack, 1967 ; Deni \& Jorgensen, 1976 ; Ganzer, 1968 ; Hunt \& Hillery, 1973; Laughlin \& Wong-McCarthy, 1975 ; Martens, 1969 ; Rajecki, Ickes, Corcoran, \& Lenerz, 1977 ; Shaver \& Liebling, 1976; Smith \& Crabbe, 1976; Zajonc, Heingartner, \& Herman, 1969) but Cunninghum and Roberts (1973), Miyamoto (1977), and Pessin and Husband (1933) do not. Recent studies were reviewed by Geen and Gange (1977) and Weiss and Miller (1971).

However, Zajonc's results made one unresolved question salient: Why is the presence of others arousing? Contrary to Zajonc's original proposals, Cottrell (1968, 1972) argued that the mere physical presence of others, or their warm bodies in the room, was not in itself sufficient to produce social facilitation, but that the others must be perceived as evaluative. It seemed that this cognition was determined by prior experiences, personalities, and cultures. Shaver and Liebling (1976) emphasized that little is known about these variables that affect the processes of social facilitation.

Thus the present experiment was designed to study the audience effects upon the performance on both the simple and the complex finger mazes with use of Japanese subjects. It was hypothesized from Zajonc's proposal 
that performance on the simple maze would be facilitated by the presence of an observer, while performance on the complex one would be impaired by the presence of an observer.

There were, however, two unique features in this experiment. First, the instructions were planned to make the subjects' awareness of being observed intense. Second, the experimenter made a record of errors at every choice point.

\section{METHOD}

Experimental design. A $2 \times 2$ experimental design was employed with maze complexity and observer conditions as independent variables. There were two levels of each factor: Simple Maze-Complex Maze; Alone-Observed.

Subjects. The subjects were 60 female students. Another 30 students served as observers. All were students from classes in educational psychology at Tokiwa Gakuen College. They were recruited for an experiment concerned with memory and learning and given credit points for their participation. Each was assigned at random to either one of four experimental conditions or observer conditions with the restriction that there be an equal number of subjects in each condition.

Apparatus. The simple maze was a multiple T-maze which had 12 choice points and 12 corresponding cul-de-sacs. The complex maze was a multiple +-maze which had 12 choice points and 24 corresponding cul-de-sacs. Both the $\mathrm{T}$ - and +-finger mazes were made by gluing matchsticks on boards $(27 \mathrm{~cm} \times 72 \mathrm{~cm})$. Two coins were also used as starting and end points. The subjects were blindfolded over their eyes and were able to solve the mazes by putting their right forefingers on the starting point and tracing the matchsticks until the end was reached.

Procedure. When the subject arrived for the experiment, the experimenter brought her into the experimental room, and had her seated at a table on which the mazes were placed with the upside down. The subject was given instructions as to the task to be performed
TABLE 1

The mean number of trials (and $S D$ s) to reach the criterion of three consecutive errorless trials under four experimental conditions

\begin{tabular}{lccc}
\hline & Alone & Observed & Mean \\
T-maze & 22.33 & 25.26 & 23.80 \\
& $(6.57)$ & $(7.25)$ & \\
+ -maze & 21.13 & 26.33 & 23.73 \\
& $(5.11)$ & $(5.54)$ & \\
Mean & 21.73 & 25.80 & \\
Note. $N=15$ in each cell.
\end{tabular}

using training mazes which had the starting, only two choice, and end points. As soon as each subject indicated her understanding of the procedure, she was asked to put the blindfold over her eyes. Then, under the experimental conditions involving an audience, another student was brought into the experimental room and sat in a chair a few feet to the left of the subject. The experimenter said to the observer, "I'm interested in the reliability of an eyewitness. Your task is to observe her behavior carefully. After this experiment, you will be asked in detail about what happened". They watched the subjects quietly and attentively. Of course, under the two "alone" conditions this use of an observer was eliminated. The experimenter was present during the experiment for all conditions. The subjects were told to trace their mazes until they reached the criterion of three consecutive errorless trials as in Husband (1931), and that the time spent and the number of errors made would be recorded by the experimenter. In the present study the subjects were allowed as many as 40 trials on their mazes.

\section{RESUlts}

Presented in Table 1 are the mean number of trials required to reach the learning criterion of three consecutive errorless trials for each condition. When these means were subjected to an analysis of variance, a significant effect was obtained for the observer conditions $(F=5.78, d f=1 / 56, p<.05)$ but not for 
'TABLE 2

The mean number of errors (and $S D_{s}$ ) under four experimental conditions

\begin{tabular}{cccc}
\hline & Alone & Observed & Mean \\
\hline T-maze & 58.79 & 66.80 & 62.80 \\
& $(20.16)$ & $(20.11)$ & \\
+ -maze & 86.00 & 110.59 & 98.30 \\
& $(23.43)$ & $(32.14)$ & \\
\hline Mean & 72.40 & 88.70 & \\
Note. $\mathcal{N}=15$ in each cell.
\end{tabular}

the task $(F<1)$. On both the $T$ - and + mazes, the subjects in the Alone conditions performed better than those in the Observed conditions. The predicted Observer $\times$ Task interaction was not significant $(F<1)$.

In terms of errors, the subjects' performance levels for the first five and the first 10 trials were analyzed separately from the total number of trials. The results of analysis of variance for these three measures were similar, so only those of the total number of errors will be reported here. Means for four experimental conditions are presented in Table 2. As in the case of the trials, the subjects in the Alone conditions performed better than those in the Observed conditions on both mazes. An analysis of variance revealed that significant effects were found for both the task $(F=29.49$, $d f=1 / 56, p<.01)$ and the observer conditions $(F=6.22, d f=1 / 56, p<.05)$. The predicted Observer $\times$ Task interaction, however, was not

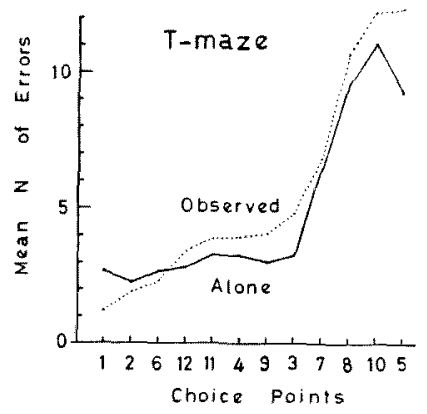

Fic. 1. Mean number of errors for two groups made at each choice point on a multiple $T$-maze. Choice points are rearranged in the order of the number of errors of the observed group. significant $(F=1.61, d f=1 / 56)$.

In this experiment, as the experimenter could check the errors at every choice point, the number of errors at each of 12 choice points were determined for each subjects. The mean number of errors are presented in Fig. 1 for the T-maze and Fig. 2 for the +-maze. A $2 \times 12$ (Observer $\times$ Choice point) analysis of variance was conducted on $\mathrm{T}$-maze scores. The choice point factor was significant $(F=$ $38.81, d f=11 / 308, p<.01)$, but the observer conditions was not significant $(F=1.10, d f=$ $1 / 28)$. The Observer $\times$ Choice point interaction was not significant $(F=1.09, d f=11 / 308)$.

For the +-maze scores, a $2 \times 12$ (Observer $\times$ Choice point) analysis of variance revealed that significant effects were found for both the observer conditions $(F=5.35, d f=1 / 28, p<$ $.05)$ and the choice points $(F=29.92, d f=$ $11 / 308, p<.01)$. The Observer $\times$ Choice point interaction was not significant $(F<1)$ either.

Finally, a $2 \times 2$ analysis of variance was performed for the results of the mean time in seconds the subjects took to traverse the mazes for the last three trials. The subjects in the Observed conditions took less time $(22.77 \mathrm{sec})$ than those of the Alone conditions $(25.37 \mathrm{sec})$. This difference was not, however, statistically meaningful $(F=2.79, d f=1 / 56)$. Neither the effects of Task nor of the interaction was significant $(F<1$, in two cases).

\section{Discussion}

On both the $T$ - and +-mazes, the subjects

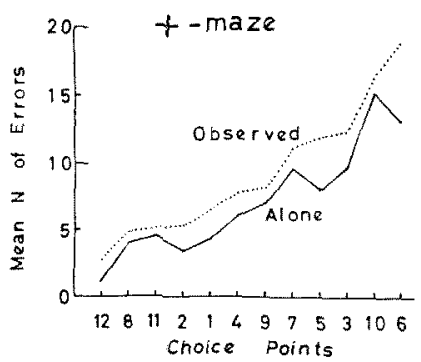

Fig. 2. Mean number of errors for two groups made at each choice point on a multiple + -maze. Choice points are rearranged in the order of the number of errors of the observed group. 
needed more trials to reach the learning criterion when observers were present than when they were absent. It seems that the 12 levels finger $\mathrm{T}$-maze is not simple but complex task. This point was not discussed in the previous researches. The subjects in the previous studies were not allowed to trace their mazes until they reached the learning criteria. They traversed their mazes only five (Shaver \& Liebling, 1976), ten (Hunt \& Hillery, 1973), or twenty times (Rajecki, et al., 1977).

The results of the error scores provide partial support for the original hypotheses. Zajonc's proposal was confirmed on the + -maze. The subjects of the Observed group made more errors as in the past studies (Hunt \& Hillery, 1973; Shaver \& Liebling, 1976) than those of the Alone group. They also made more errors at every choice point. The dominant response on the +-maze was incorrect, therefore the presence of the observer facilitated the emission of the dominant responses.

The failure to obtain evidence of facilitated performance on the $\mathrm{T}$-maze in the observer condition is clearly inconsistent with previous researches (Hunt \& Hillery, 1973 ; Shaver \& Liebling, 1976; Rajecki, et al., 197\%). There are several possible explanations for this failure: First, obtained differences are due to cross-cultural differences. Second, for the present population the 12 levels finger $T$-maze is not truly simple. And, third, there is a procedual difference: In this experiment the subjects traversed the mazes wearing blindfolds, unlike above previous studies.

Pessin and Husband (1933) used a tenturn multiple-U high-relief finger maze to compare performances of the subjects working with blindfolds and the subjects with vision allowed. One or two observers were present in both conditions. They found that maze performances of the vision-allowed group were better when compared to performances of the subjects in the blindfold condition, but these differences were statistically insignificant. These results suggest that since the subjects in the vision-allowed condition (as in the above previous studies) had more information than those in the blindfold condition (as in this experiment), they could traverse the maze more easily.

The other explanation is possible for these results. That is Cottrell's learned drive theory. It seems that the subjects in the Observed groups had the awareness of being observed, so that the anticipated evaluation is responsible for increasing their drive level. However, this study did not provide a direct test of this hypothesis.

\section{REFERENCES}

Cotrrell, N. B. 1968 Performance in the presence of other human beings: Mere presence, audience, and affiliation effects. In E.C. Simmel, R. A. Hoppe, \& G. A. Milton (Eds.) Social facilitation and imitative behavior. Boston: Allyn \& Bacon. Pp. 91-110.

Cotrrelt, N.B. 1972 Social facilitation. In C. G. McClintock (Ed.) Experimental social psychology. New York: Holt, Rinehart \& Winston. Pp. 185-236.

Cottrell, N. B., Rittle, R. H., \& Wack, D. L. 1967 The presence of an audience and list type (competitional or noncompetitional) as joint determinants of performance in pairedassociates learning. Journal of Personality, 35, 425 434.

Cunningham, W. L., Jr., \& Roberts, A. E. 1973 Acquisition and maintenance of Sidman avoidance with paired rat subjects. Animal Learning and Behavior, 1, 44-48.

Dent, R., \& Jorgensen, B.W. 1976 Social inhibition of barpressing in undeprived rats. Bulletin of the Psychonomic Society, 7, 487-488.

GANZER, V.J. 1968 Effects of audience presence and test anxiety on learning and retension in a serial learning situation. Journal of Personality and Social Psychology, 8, 194-199.

Geen, R. G., \& Gange, J. J. 1977 Drive theory of social facilitation: Twelve years of theory and research. Psychological Bulletin, 84, 1267 1288.

Laughlin, P.R., \& Wong-McCarthy, W.J. 1975 Social inhibition as a function of observation and recording of performance. Journal of Experimental Psychology, 11, 560-571.

Hunt, P.J., \& Hillery, J. M. 1973 Social facilitation in a coaction setting: An examination of the effects over learning trials. 
Journal of Experimental Social Psychology, 9, 563571.

Husband, R. W. 1931 Analysis of methods in human maze learning. Journal of Genetic Psychology, 39, 258-277.

Martens, R. 1969 Effect of an audience on learning and performance of a complex motor skill. Fournal of Personality and Social Psychology, 12, 252-260.

Mryamoto, M. 1977 Effects of being observed on paired associate learning. The Bulletin of Tokiwa Gakuen College, 6, 77-82. (In Japanese with English abstract)

Pessin, J., \& Husband, R.W. 1933 Effects of social stimulation on human maze learning. Journal of Abnormal and Social Psychology, 28, 148-154.

Rajecki, D. W., Ickes, W., Corcoran, C., \& LENERz, K. 1977 Social facilitation of human performance: Mere presence effects. The Journal of Social Psychology, 102, 297-310.
Shaver, P., \& Liebling, B. A. 1976 Explorations in the drive theory of social facilitation. The Journal of Social Psychology, 99, 259-271.

Smith, L. E., \& Crabbe, J. 1976 Experimenter role relative to social facilitation and motor learning. International Journal of Sport Psy. chology, 7, 158-168.

Weiss, R. F., \& Miller, F. G. 1971 The drive theory of social facilitation. Psychological Review, 78, 44-57.

ZAjonc, R.B. 1965 Social facilitation. Science, 149, 269-274.

Zajonc, R. B. 1969 Social psychology: An experimental approach. Belmont, Calif.: Wadsworth.

Zajonc, R. B., Herngartner, A., \& Herman, E. M. 1969 Social enhancement and im. pairment of performance in the cockroach. Joumal of Personality and Social Psychology, 13, 83-92.

(Received May 16, 1978) 